\title{
MAR1 suppresses inflammatory response in LPS-induced RAW 264.7 macrophages and human primary peripheral blood mononuclear cells via the SIRT1/PGC-1a/ PPAR- $\gamma$ pathway
}

\author{
Wei Wang ${ }^{1 * \dagger}$ (D), Rong-Li Xu ${ }^{2+}$, Ping He ${ }^{1}$ and Rui Chen ${ }^{3^{*}}$
}

\begin{abstract}
Background: Sepsis is a complex syndrome characterized by a dysregulated inflammatory response to systemic infection and leads to shock, multiple organ failure and death especially if not recognized early and treated promptly. Previous studies have suggested Maresin 1 (MAR1) can alleviate systemic inflammation in sepsis, but its mechanism has not been clarified.

Methods: RAW 264.7 cells and human primary peripheral blood mononuclear cells (hPBMCs) were pretreated with LPS and MAR1. The mRNA expression and supernatant levels of pro-inflammatory cytokines, tumor necrosis factor (TNF-a), interleukin (IL)-1 $\beta$ and IL-6 were evaluated by RT-qPCR and ELISA, respectively. The expression levels of Sirtuin 1 (SIRT1), peroxisome proliferator-activated receptor $y$ coactivator-1a (PGC-1a), and Peroxisome proliferatoractivated receptor gamma (PPAR- $\gamma$ ) were determined by RT-qPCR and Western blot analysis, respectively.

Results: Our results show that LPS-induced inflammation increased the expression and secretion of proinflammatory cytokines TNF- $a, \mathrm{IL}-1 \beta$ and IL- 6 and induced suppression of SIRT1, PGC-1a, and PPAR- $\gamma$ expression, which could be reversed by MAR1. And the effect of MAR1 was eliminated by repression of SIRT1/PPAR- $y$ and enhanced by PGC-1a overexpression.
\end{abstract}

Conclusions: MAR1 suppressed inflammatory response in LPS-induced RAW 264.7 macrophages and hPBMCs via the SIRT1/PGC-1a/PPAR- $\gamma$ pathway.

Keywords: MAR1, SIRT1, PGC-1a, PPAR- $\gamma$, Sepsis

\footnotetext{
* Correspondence: ww_smile@qq.com; crui_rui@126.com

'Wei Wang and Rong-Li Xu are the co-first authors.

'Department of Emergency, Hainan General Hospital, Hainan Affiliated Hospital of Hainan Medical University, No.19, Xiuhua Road, 570311 Haikou, Hainan Province, People's Republic of China

${ }^{3}$ Department of Medical Intensive Care Unit, General Hospital of Southern Theater Command, PLA, No.111, Liuhua Road, 510010 Guangzhou, People's Republic of China

Full list of author information is available at the end of the article
}

C C The Author(s). 2021 Open Access This article is licensed under a Creative Commons Attribution 4.0 International License, which permits use, sharing, adaptation, distribution and reproduction in any medium or format, as long as you give appropriate credit to the original author(s) and the source, provide a link to the Creative Commons licence, and indicate if changes were made. The images or other third party material in this article are included in the article's Creative Commons licence, unless indicated otherwise in a credit line to the material. If material is not included in the article's Creative Commons licence and your intended use is not permitted by statutory regulation or exceeds the permitted use, you will need to obtain permission directly from the copyright holder. To view a copy of this licence, visit http://creativecommons.org/licenses/by/4.0/. The Creative Commons Public Domain Dedication waiver (http://creativecommons.org/publicdomain/zero/1.0/) applies to the data made available in this article, unless otherwise stated in a credit line to the data. 


\section{Introduction}

Sepsis, defined as a syndrome of systemic inflammatory response (SIRS) caused by infection as a result of an infective process, is a rapidly progressive and lifethreatening syndrome. Severe sepsis with multiple organ dysfunctions is still the main cause of death in intensive care unit patients [1, 2]. During sepsis, inflammation response can be activated in both macrophages and monocytes, and the inflammatory factors released by macrophages may accelerate the sepsis-induced cell and tissue injury [3, 4]. Lipopolysaccharide (LPS), a component of the outer membrane of Gram-negative bacteria, interacts with specific receptors on host effector cells and induces the release of proinflammatory cytokines [5]. Excessive production of these cytokines can lead to an uncontrolled inflammatory response [6]. Therefore, LPS is widely held to be a mediator of the inflammatory events associated with sepsis [7]. LPS-treated macrophages were adopted as an in vitro model of endotoxininduced inflammation during sepsis [8], such as using the murine macrophage cell line RAW264.7 [9, 10].

Specialized pro-resolving mediators such as resolvins, protectins, and maresins, actively turn off the inflammatory response by acting on different $\mathrm{G}$ protein-coupled receptors expressed on immune cells that activate the dual anti-inflammatory process [11]. Maresin 1 (MAR1) from polyunsaturated fatty acids is one of the most recently identified members of the family of antiinflammatory lipid mediators and has shown antiinflammatory and proresolving activity in zymosan-induced peritonitis [12]. Many studies have shown that MAR1 shows proresolving and anti-inflammatory effects in a variety of diseases [12-14]. However, the specific mechanism of its role in sepsis remains unclear. In previous studies, MAR1 has been shown to reduce proinflammatory response and mitochondrial damage by activating SIRT1 signaling to protect mouse brain tissue and neurons from ischemia/reperfusion injury $[15,16]$. A large number of studies have shown that sirtuin 1 (SIRT1) is a highly conserved mammalian $\mathrm{NAD}(+)$-dependent protein deacetylase and is involved in multiple biological processes [17]. Therefore, it is not surprising that the changes in SIRT1 activity or expression profile are strongly correlated with metabolic processes, oxidative stress, and the pathogenesis of inflammation [17, 18]. Furthermore, SIRT1 knockout mice have increased sensitivity to septic-induced inflammatory lung injury [19, 20]. Meanwhile, SIRT1 suppresses acute lung inflammation during sepsis by controlling the activation of inflammatory pathway [21], so it is highly possible that MAR1 reduce the inflammatory response by activating SIRT1 in sepsis. Peroxisome proliferator-activated receptor- $\gamma$ co-activator$1 \alpha(\mathrm{PGC}-1 \alpha)$ is one of the three known co-activators in the
PGC-1 family [22], it can bind to multiple transcription factors, effectively promote mitochondrial biogenesis and reduce mitochondrial damage [23]. PGC-1 $\alpha$ can not only be activated by SIRT1 through deacetylation, but also act as a transcription coactivator to enhance the activity of peroxisome proliferator-activated receptor $\gamma$ (PPAR $\gamma$ ) [24, 25]. PPAR $\gamma$ is a member of the nuclear receptor superfamily of ligand-induced transcription factors, which mainly controls gene expression involved in adipogenesis, lipid metabolism, and inflammation [26]. Likewise, PPAR- $\gamma$ activation is an effective intervention to prevent or restore septic myocardial dysfunction and has proven to be a promising treatment strategy for sepsis [27]. From this result, we initially proposed that MAR1 reduces the inflammation response in sepsis may be related to the activation of SIRT1/PGC-1 $\alpha$ / PPAR- $\gamma$ axis.

In our current study, the relationship between reduction of inflammatory response by MAR1 and SIRT1/ PGC- $1 \alpha /$ PPAR- $\gamma$ signaling axis was systematically investigated and intended to explain the specific mechanism of MAR1 in in vitro sepsis models of LPS-induced RAW 264.7 cells and human primary peripheral blood mononuclear cells (hPBMCs).

\section{Materials and methods \\ Cell culture and treatment}

The mouse mononuclear macrophage leukemia cell line RAW264.7 was purchased from the American Type Culture Collection (ATCC), and primary human peripheral blood mononuclear cells (hPBMCs) was purchased from PriCells (Wuhan, China). Cells were cultured in DMEM containing $10 \%$ fetal bovine serum (FBS, Gibco; Thermo Fisher Scientific) and $1 \%$ penicillin (100 U/ $\mathrm{mL}) /$ streptomycin $(100 \mu \mathrm{g} / \mathrm{mL}$ ) (Hyclone; GE Healthcare Life Sciences) in a $37^{\circ} \mathrm{C}$ in an incubator containing $5 \%$ $\mathrm{CO}_{2}$ at $37{ }^{\circ} \mathrm{C}$. For establishment of in vitro model, lipopolysaccharide (LPS, $10 \mu \mathrm{g} / \mathrm{mL}$, Sigma-Aldrich, St. Louis, MO, USA) was used to treat the cells for $24 \mathrm{~h}$. For treatment of MAR1, cells were treated with different concentrations (0.1 nM, $1 \mathrm{nM}, 10 \mathrm{nM}$ and $100 \mathrm{nM})$ of MAR1 (cat. No. HY-116,429; MedChemExpress, NJ, USA) for $12 \mathrm{~h}$ before LPS treatment. For analysis of time effects, cells were treated with $10 \mathrm{nM}$ MAR1 with different time duration ( $0 \mathrm{~h}, 4 \mathrm{~h}, 6 \mathrm{~h}, 8 \mathrm{~h}$ and $12 \mathrm{~h}$ ).

\section{Real-time qPCR analysis}

Total RNA was extracted from cells using TRIzol reagent (Invitrogen). After total RNA was reverse transcribed into cDNA by using a Prime-Script ${ }^{\mathrm{Tm}}$ One Step RT-qPCR kit (Takara Biotechnology Co., Ltd., Dalian, China), PCR reactions for SIRT1, PGC-1 $\alpha$, PPAR- $\gamma$, IL-1 $\beta$, IL-6 and TNF- $\alpha$ mRNA were performed on a LightCycler 480 (Roche, Mannheim, Germany) system with GAPDH used as an internal control. The light 
cycler DNA master SYBR green I kit (Roche Molecular Biochemicals, Mannheim, Germany) was then used for PCR experiments. The following primers were used: SIRT1 Forward: 5' -GGTGTTAAATACCAAACTGC-3' and reverse: 5'-AGGAGTGATGTTCAAAATG-3'; PGC$1 \alpha$ Forward: 5'-AATTCACAATCACAGGATCAGAACA3' and reverse: 5'-ACTTAAGGTGCGTTCAATAGTCTT-3'; PPAR- $\gamma$ Forward: 5'-TTGGCCATATTTATAGCTGTCA TTATT-3' and reverse: 5'- TGTCCTCGATGGGCTTCA3'; TNF- $\alpha$ Forward: 5'-GAGCTGTGGGGAGAACAAAA GGA-3' and reverse: 5'- TTGGCCCTTGAAGAGGAC CTG-3'; IL-1 $\beta$ Forward: 5'-GAC CTT CCA GGA TGA GGA CA-3' and reverse: 5'-AGC TCATATGGGTCCGA CAG-3'; IL-6 Forward: 5'-TCC AGT TGC CTTCTT GGG AC-3' and reverse: 5'-GTGTAATTAAGCCTCCGA CTTG-3'; GAPDH Forward: 5'-AGAAGGCTGGGGCTCA TTTG-3' and reverse: 5'-AGGGGCCATCCACAGTCT $\mathrm{TC}-3$. The relative expression of the target genes was calculated using the $2^{-\Delta \Delta \mathrm{Ct}}$ method. All experiments were repeated in triplicate.

\section{ELISA assay}

The contents of IL- $1 \beta$, IL- 6 and TNF- $\alpha$ in the cell supernatant were determined using an ELISA assay. Centrifuge at $4000 \mathrm{r} / \mathrm{min}$ for $15 \mathrm{~min}$ at $4{ }^{\circ} \mathrm{C}$ to collect the supernatant. ELISA kits were obtained from Boster (Boster Biological Technology, Wuhan, China), and each sample was measured three times according to the manufacturer's instructions.

\section{Western blot analysis}

Cells were washed in phosphate-buffered saline (PBS), then in $10 \mathrm{mM}$ TrisHCl (pH7.5), $100 \mathrm{mM} \mathrm{NaCl}, 1 \%$ NP-40, $50 \mathrm{mM} \mathrm{NaF}, 2$ mMEDTA (pH8.0), 1 mM PMSF, Cells were lysed in $10 \mu \mathrm{g} / \mathrm{mL}$ leupeptin, and $10 \mu \mathrm{g} / \mathrm{mL}$ aprotinin. The mixture was collected as a whole cell extract. The protein extract was separated by sodium lauryl sulfate polyacrylamide gel electrophoresis (SDS-PAGE) and transferred to a polyvinylidene fluoride (PVDF) membrane (immunoblotted PVDF membrane, Bio-Rad). The membrane was blocked with Tris buffered saline and $3 \%$ bovine serum albumin (BSA) in Tween 20 (TBST, pH 7.4) for $1.5 \mathrm{~h}$, and then specific primary antibodies with SIRT1, PGC- $1 \alpha$ and PPAR- $\gamma$ treated at $4{ }^{\circ} \mathrm{C}$ overnight. GAPDH was used as a protein-loading control. All antibodies were purchased from Proteintech (ProteinTech Group, Chicago, IL, USA.) The membrane was then treated with horseradish peroxidase (HRP) -conjugated secondary antibody $(1: 1,000)$ for $2 \mathrm{~h}$. The bands were visualized using an enhanced chemiluminescence system (ECL, Thermo Fisher Scientific) and LAS image software (Fuji, New York, New York, USA).

\section{Cell transfection}

GenePharma (Shanghai, China) synthesized PGC-1 $\alpha$ overexpression, sh-Sirt1 vector, sh-PPAR- $\gamma$ vector and corresponding negative controls. Cells $\left(3 \times 10^{5}\right)$ were seeded into 6-well plates for cell transfection after cell confluence of $40-60 \%$. Replace with new medium and prepare cell transfection buffer. Incubate $5 \mu \mathrm{L} /$ Wells of lipofectamine 2000 (Thermo, USA) and $250 \mu \mathrm{L}$ of OptiMEM medium (Gibco, USA) for $5 \mathrm{~min}$ at room temperature and mix with PGC-1 $\alpha$, sh-Sirt1 vector, shPPAR- $\gamma$ vector and negative control $(5 \mu \mathrm{L} /$ well $) 250 \mu \mathrm{L}$ of Opti-MEM medium for $20 \mathrm{~min}$. Then, inoculate the cells into a 6-well plate and incubate in the incubator for $6 \mathrm{~h}$. Then, the cells are incubated in $10 \%$ FBS continuous culture in new DMEM medium (Gibco, USA).

\section{Statistical analysis}

Each experiment was repeated at least 3 times. Data were analyzed using GraphPad Prism 6 (GraphPad software, San Diego, California, USA). The data were expressed as mean $\pm \mathrm{SD}$. with either unpaired two-tailed t-test or one-way ANOVA as appropriate. $P<0.05$ was considered statistically significant.

\section{Results}

MAR1 inhibited the inflammatory response of RAW264.7 cells and hPBMCs induced by LPS in a dose-dependent manner

LPS endotoxins are widely used as experimental models of systemic bacterial infection and trigger inflammatory factors such as TNF- $\alpha$, IL- $1 \beta$ and IL-6 [28]. The changes of inflammatory factors in LPS-treated RAW264.7 cells and hPBMCs under the intervention of different concentrations of MAR1 were analyzed by RT-qPCR. And we found that MAR1 inhibited the LPS-induced increase of the mRNA levels of proinflammatory factors in a dosedependent manner in both RAW264.7 cells and hPBMCs (Fig. 1a). Next, we tested the secretion of proinflammatory factors TNF- $\alpha$, IL- $1 \beta$, and IL- 6 in LPSinduced RAW264.7 cells and hPBMCs and the effect of MAR1 on their secretion. The results showed that LPS increased secretion of TNF- $\alpha$, IL- 6 and IL-1 $\beta$ in both RAW264.7 cells and hPBMCs, which can be reversed by MAR1 in a dose-dependent manner (Fig. 1b). In addition, we also performed Western blot assay to evaluate the levels of SIRT1, PGC- $1 \alpha$ and PPAR- $\gamma$ protein, and the results showed that the expression of SIRT1, PGC- $1 \alpha$ and PPAR- $\gamma$ protein were significantly down-regulated in both RAW264.7 cells and hPBMCs caused by LPS $(p<0.001)$ (Fig. 1c) and upregulated by MAR1 in a dose-dependent manner. These results indicate that MAR1 reduces the inflammatory response of RAW264.7 cells and hPBMCs induced by LPS in a dose-dependent manner. 

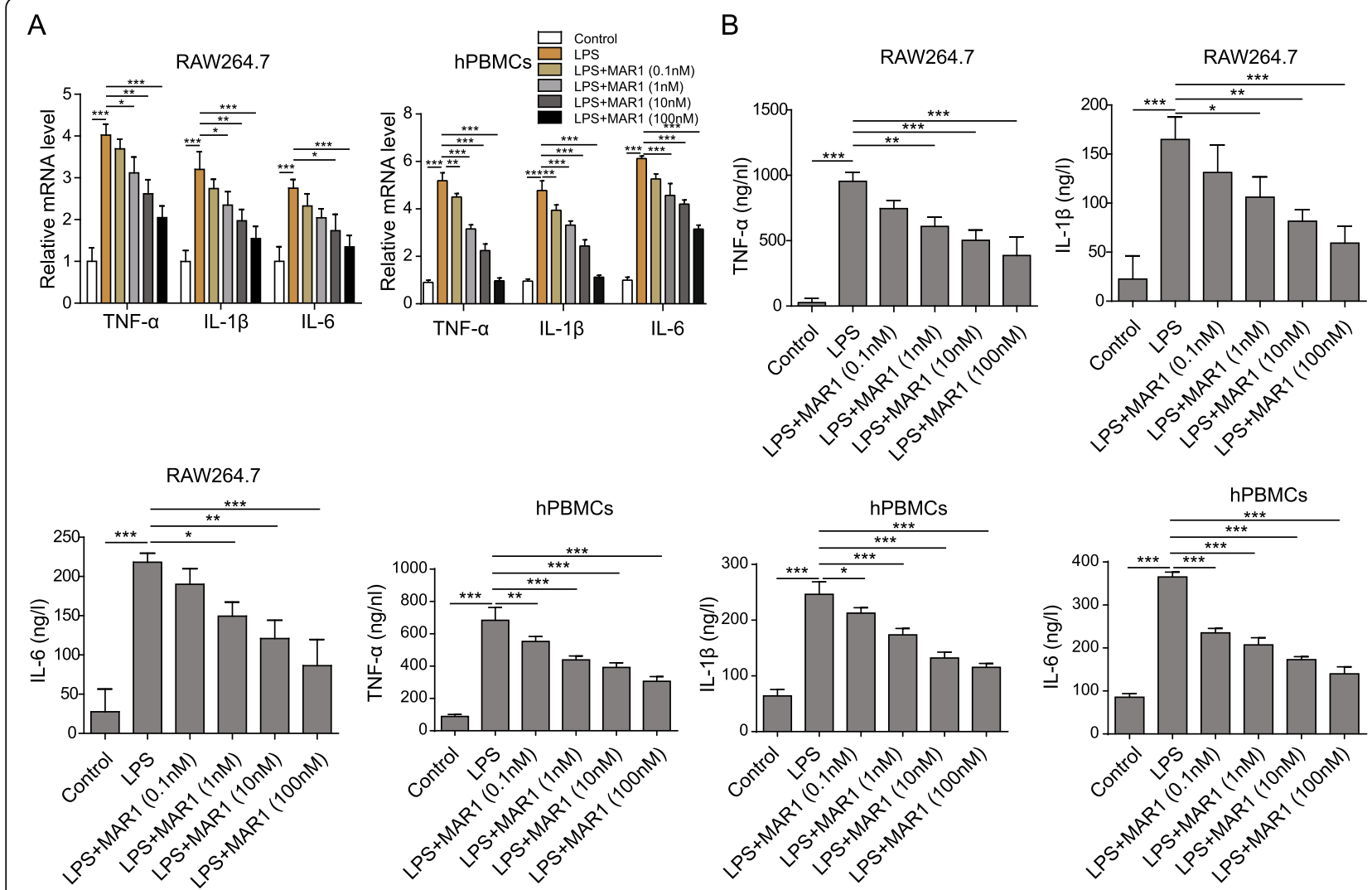

C
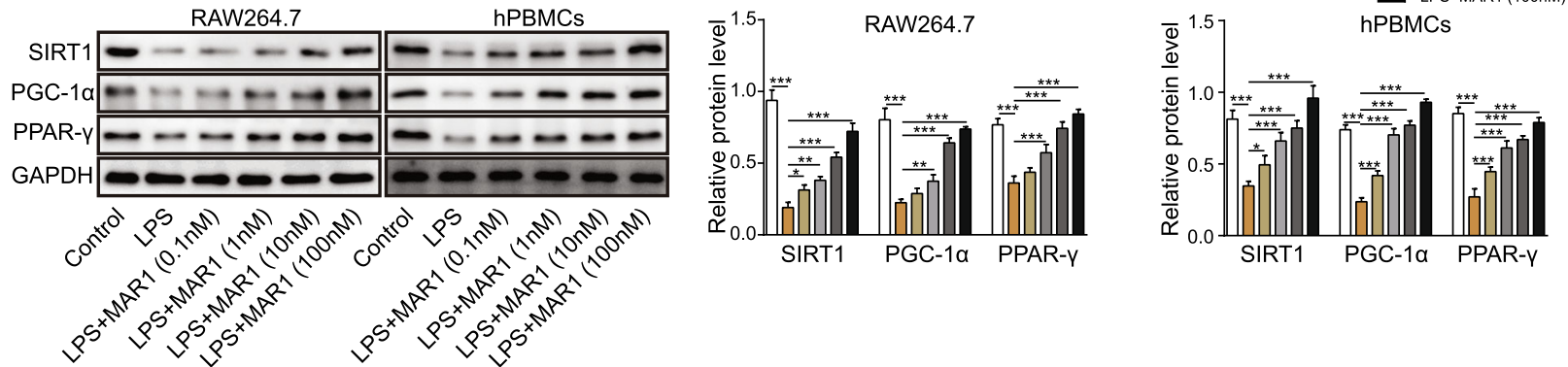

Fig. 1 MAR1 inhibited the inflammatory response of RAW264.7 cells and hPBMCs induced by LPS in a dose-dependent manner. RAW264.7 cells and hPBMCs were pretreated with different concentrations $(0.1 \mathrm{nM}, 1 \mathrm{nM}, 10 \mathrm{nM}$ and $100 \mathrm{nM})$ of MAR1 for $12 \mathrm{~h}$ and then exposed to LPS $(10 \mu \mathrm{g} / \mathrm{mL})$ for $12 \mathrm{~h}$. $\mathbf{a}$, TNF- $a, \mathrm{IL}-1 \beta$ and IL-6 expression were detected by RT-qPCR; $\mathbf{b}$, TNF- $\mathrm{a}$, IL-1 $\beta$ and IL-6 secretion were measured using ELISA. c, The protein levels of SIRT1, PGC-1a and PPAR- $\gamma$ were evaluated by Western blot. Data were shown as the means \pm SD. Each experiment was repeated in triplicate. ${ }^{*} p<0.05,{ }^{* *} p<0.01,{ }^{* * *} p<0.001$

MAR1 inhibited the inflammatory response of RAW264.7 cells and $\mathrm{hPBMC}$ induced by LPS in a time-dependent manner

The above results indicate that MAR1 reduces the inflammatory response of both RAW264.7 cells and hPBMCs induced by LPS in a dose-dependent manner especially at the highest concentration of $100 \mathrm{nM}$. We then consider investigated cells treated by $10 \mathrm{nM}$ MAR1 by different time duration $(0 \mathrm{~h}, 4 \mathrm{~h}, 6 \mathrm{~h}, 8 \mathrm{~h}$ and $12 \mathrm{~h}$ ). The changes of inflammatory factors in LPS-treated RAW264.7 cells and hPBMCs at different intervention time $(0 \mathrm{~h}, 4 \mathrm{~h}, 6 \mathrm{~h}, 8 \mathrm{~h}$ and $12 \mathrm{~h})$ of MAR1 were analyzed by RT-qPCR. And we demonstrated that MAR1 inhibited the LPS-induced increase of the mRNA levels of proinflammatory factors in both RAW264.7 cells and hPBMCs with the treatment time (Fig. 2a). Then, we tested the secretion of TNF- $\alpha$, 


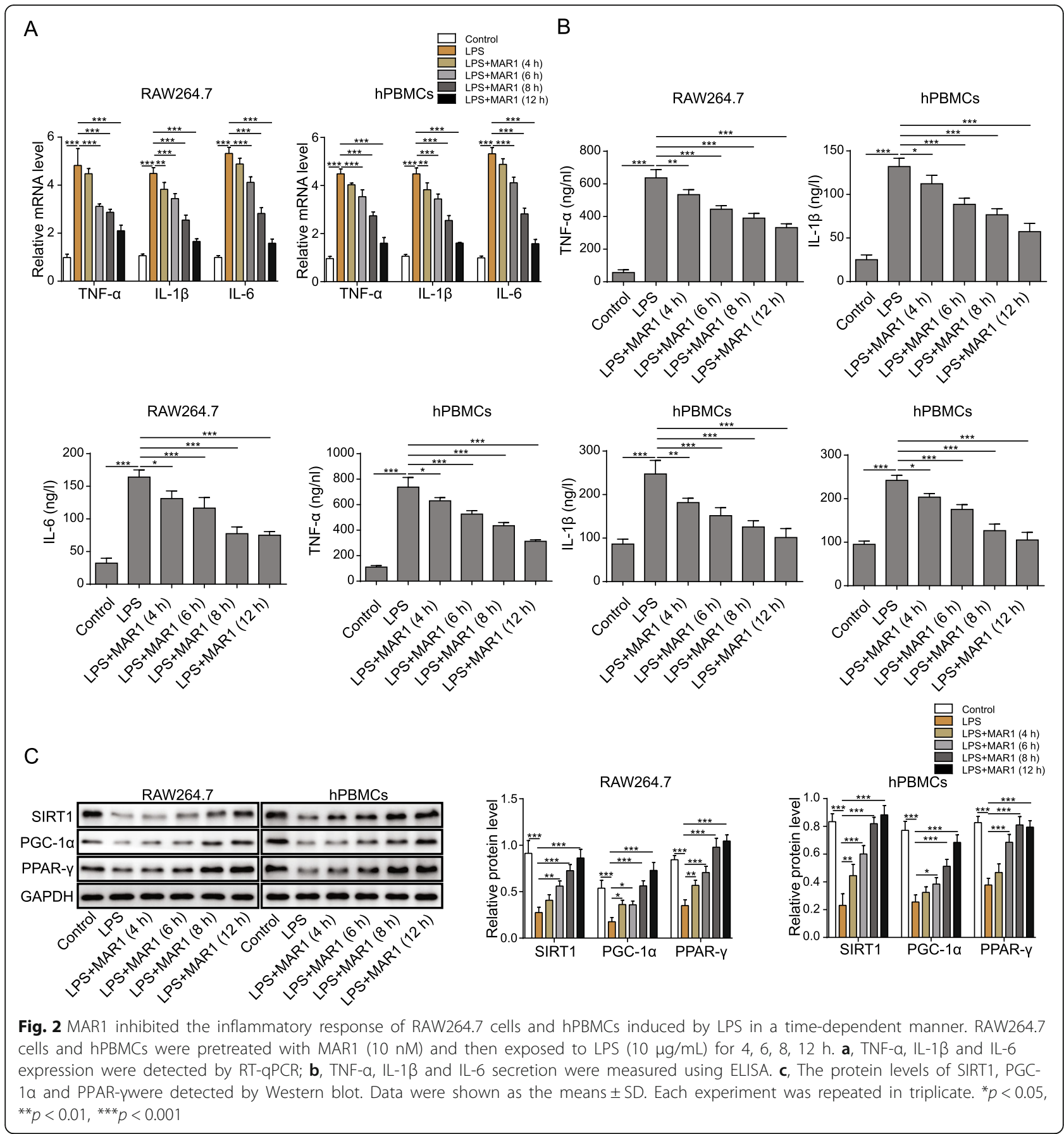

IL-1 $\beta$, and IL-6 in LPS-induced RAW264.7 cells or hPBMCs and the effect of MAR1 on their secretion. The results showed that LPS increased the secretion of TNF- $\alpha$, IL- 6 and IL-1 $\beta$ in both RAW264.7 cells and hPBMCs, which can be reversed by MAR1 $(10 \mathrm{nM})$ (Fig. 2b). Thus, MAR1 reduced the levels of inflammatory factors with the treatment time. Additionally, we also performed the Western blot to evaluate the levels of SIRT1, PGC- $1 \alpha$ and PPAR- $\gamma$ protein, and the results showed that the expression of SIRT1, PGC-1 $\alpha$ and PPAR- $\gamma$ were significantly down-regulated in both RAW264.7 cells and hPBMCs induced by LPS $(p<$ 0.001) (Fig. 2c) and were upregulated by MAR1 $(10 \mathrm{nM})$ in a time-dependent manner. These results indicate that MAR1 reduces the inflammatory response induced by LPS in a time-dependent manner. 
PPAR- $\gamma$ knockdown suppressed the effect of MAR1 on LPS-induced inflammatory response in RAW264.7 cells and hPBMCs

Previous results revealed a possible mechanism for MAR1 in LPS-induced sepsis and inhibited inflammatory response in RAW264.7 cells or hPBMCs. In order to verify the role of PPAR- $\gamma$ in the effect of MAR1 on LPS-induced sepsis, sepsis model of RAW264.7 cells and hPBMCs were induced by LPS and MAR1 $(10 \mathrm{nM})$ for $12 \mathrm{~h}$ after sh-PPAR- $\gamma$ and control vectors were stalely transfected. The results of RT-qPCR showed that the mRNA expression of PPAR- $\gamma$ was markedly suppressed following transfection with the shRNA-containing vector (Fig. 3a). Both mRNA and protein levels of PPAR- $\gamma$ significantly were decreased by LPS treatment, and this effect could be blocked by

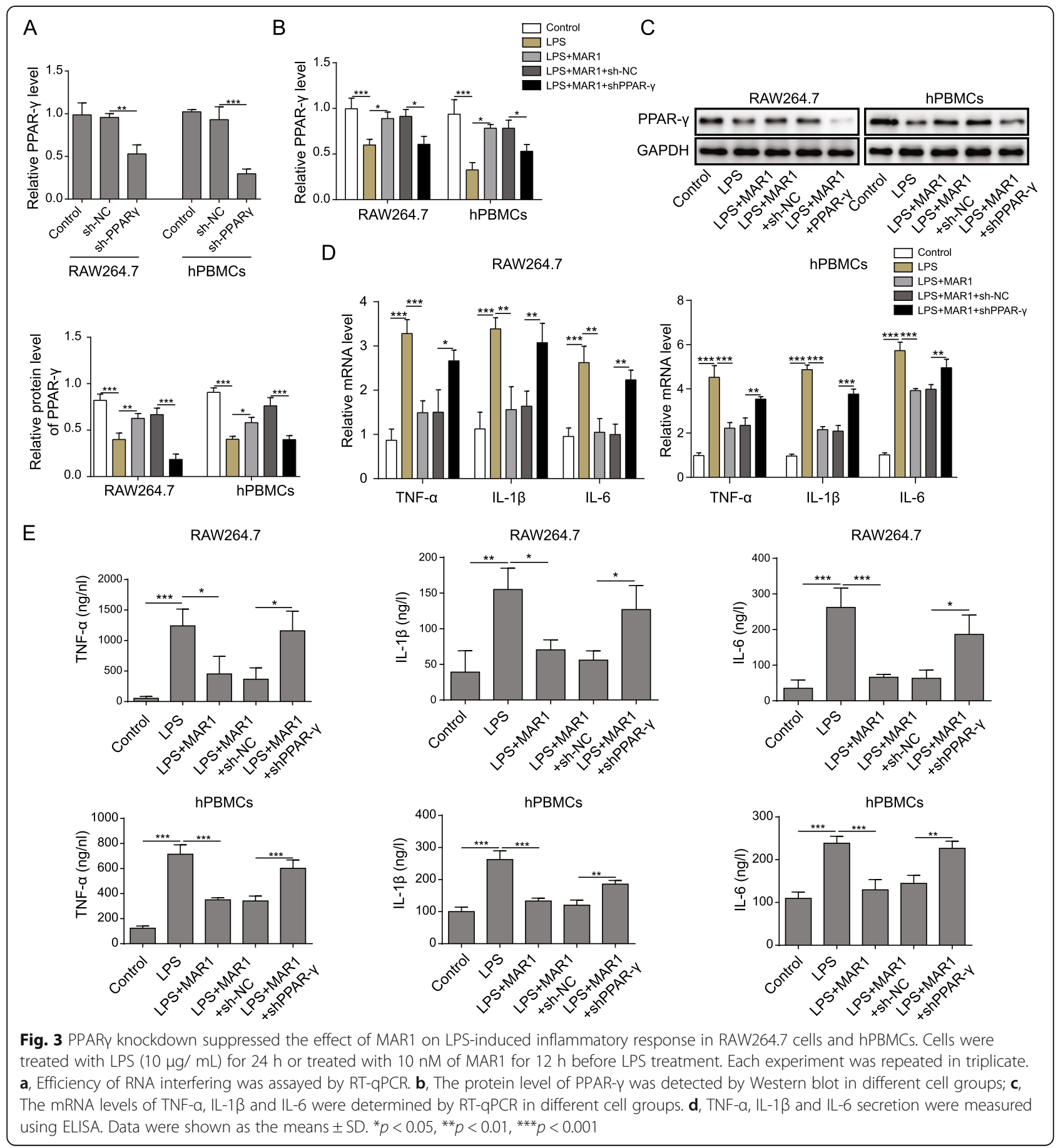


MAR1 treatment, which was further reversed by PPAR $-\gamma$ knockdown (Fig. $3 \mathrm{~b}$ and c). Both mRNA expression and protein levels of pro-inflammatory factors were suppressed under the action of MAR1 in LPS-induced RAW264.7 cells and hPBMCs, and the changes were reversed in cells with knockdown of PPAR $-\gamma$ (Fig. 3d and e). Therefore, inhibition of PPAR- $\gamma$ can offset the effect of MAR1 on inflammatory response in LPS-induced sepsis model.

\section{MAR1 suppressed inflammatory response in LPS-induced RAW 264.7 cells and hPBMCs via the SIRT1/PGC-1a/PPAR- Y pathway}

The expression of TNF- $\alpha$, IL- $1 \beta$, and IL- 6 induced by LPS were significantly reduced after treatment with MAR1 $(P<0.001)$, the effect of MAR1 can be counteracted by SIRT1 knockdown and further enhanced by PGC-1 $\alpha$ overexpression (Fig. 4a). The changes in secretion of pro-inflammatory factors were examined by ELISA experiments. Secretion of TNF- $\alpha$, IL- $1 \beta$ and IL- 6 induced by LPS were significantly reduced after treatment with MAR1 $(P<0.001)$, the effect of MAR1 can be abolished by SIRT1 knockdown and further augmented by PGC- $1 \alpha$ overexpression (Fig. 4b). Additionally, the mRNA and protein results in both RAW264.7 cells and hPBMCs showed that the expression of SIRT1, PGC- $1 \alpha$ and PPAR- $\gamma$ in the LPS group were significantly lower than those in the control group $(P<0.001)$, while MAR1 could restore their expression, and the effect of MAR1 can be counteracted by SIRT1 knockdown and further enhanced by PGC$1 \alpha$ overexpression (Fig. $4 \mathrm{c}$ and $\mathrm{d}$ ). These results indicate that MAR1 suppressed inflammatory response on LPS-induced sepsis via the SIRT1/PGC- $1 \alpha /$ PPAR- $\gamma$ pathway.

\section{Discussion}

More and more studies have proved that using LPSstimulated cells to establish an in vitro inflammation model can more closely study sepsis and LPS-treated macrophages were adopted as an in vitro model of endotoxin-induced inflammation during sepsis $[9,29$, 30]. Recently, some studies have shown that MAR1 has a protective effect against inflammatory response by affecting SIRT1-mediated signaling pathway [31]. However, its underlying mechanism remains to be elucidated. In this study, we found that MAR1 attenuated inflammatory response by regulating the expression and secretion of LPS-induced proinflammatory cytokines. In addition, we also demonstrated that MAR1 increased SIRT1, PGC- $1 \alpha$, and PPAR- $\gamma$ expression in RAW264.7 cells and hPBMCs. Then the cells were transfected with sh-SIRT1 or sh- PPAR- $\gamma$ vector and PGC-1 $\alpha$ overexpression vector to study the mechanism by which MAR1 abolish LPS-induced cellular inflammation. Therefore, this study aimed to determine the effect of MAR1 on inflammatory response and the relationship between MAR1 and SIRT1/PGC$1 \alpha /$ PPAR $-\gamma$ axis in RAW264.7 cells and hPBMCs induced by LPS.

Sepsis is considered a serious disease with multiple organ damage caused by uncontrollable inflammation in severe infections, while MAR1 plays a role in reducing the bacterial burden and mitigating excessive inflammatory response and increases the survival rate of sepsis mice [32]. The study by $\mathrm{Li}$ et al. also suggests that the protective effect of MAR1 on sepsis may partly be related to the inhibition of the activation of NF- $k B$ that causes increased proinflammatory cytokines such as IL-6, IL-1 $\beta$ and TNF- $\alpha$ in a mice model [33]. In addition, MAR1, as one of the newly discovered antiinflammatory and pro-degradation mediators, can inhibit the infiltration and adhesion of neutrophils, enhance the macrophage phagocytosis of necrotic cells, down-regulate the production of inflammatory mediators and induce the GSK3 $\beta$ anti-inflammatory axis in human monocytes to limit the excessive development of inflammation and promote the timely resolution of inflammation[34, 35]. Our study shows for the first time that MAR1 can reduce the expression and secretion of pro-inflammatory factors and has shown protection against LPS-induced RAW264.7 cell and hPMBCs sepsis model.

There is evidence that increased expression of SIRT1 can reduce multiple organ damage, including lung, kidney, and liver, caused by sepsis [36, 37]. Interestingly, by activating SIRT1, MAR1 treatment exerted a neuroprotective effect in mice and thus had a therapeutic effect on cerebral ischemia-reperfusion injury [15]. Therefore, the protective effect of MAR1 on LPSinduced cellular inflammation in this study suggests that MAR1 may reduce the inflammatory response by activating SIRT1. In addition, the anti-inflammatory effects of SIRT1 in preventing multiple inflammatory response can be attributed to the activation of PGC$1 \alpha$ and the down-regulation of NF- $\kappa B$ [38]. PPAR- $\gamma$ is a ligand-activated transcription factor involved in cell proliferation, lipid metabolism and inflammation. It has been shown to be a regulator of multiple inflammatory responses and activated PPAR- $\gamma$ can improve survival in sepsis animals [27, 39]. Obviously, SIRT1 can reduce the production of various proinflammatory cytokines by activating PGC- $1 \alpha$ and inhibiting NF- $\mathrm{kB}$ activation to reduce the acute inflammatory response in tissue injury [40]. In this study, we demonstrated that the levels of SIRT1, PGC- $1 \alpha$, and PPAR- $\gamma$ protein involved in anti-inflammatory action were reduced in RAW264.7 cells and hPBMCs induced by LPS, while 
A
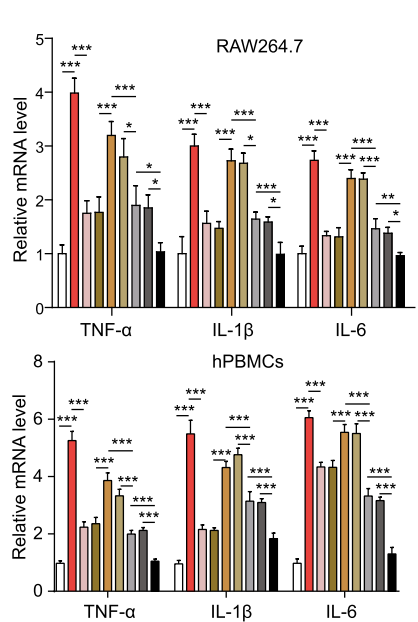

B
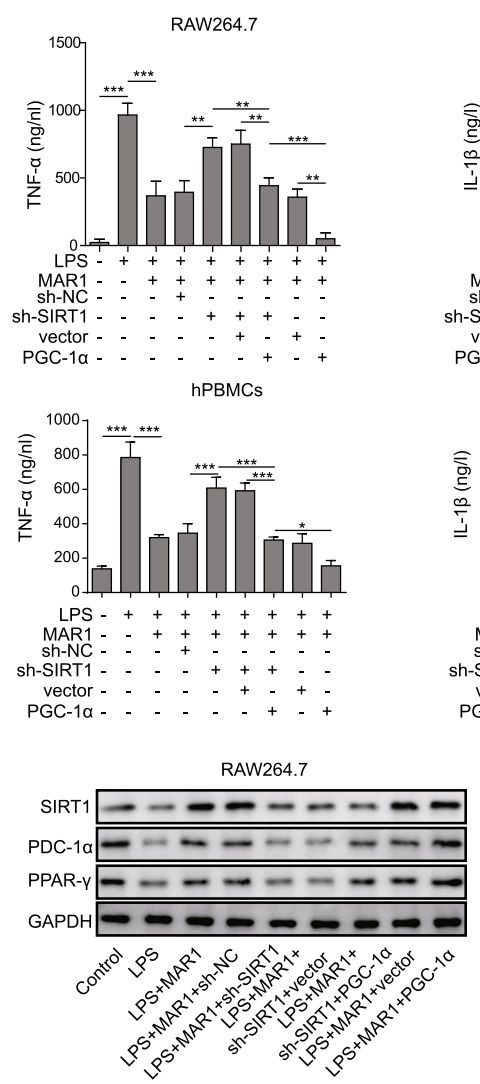

hPBMCs

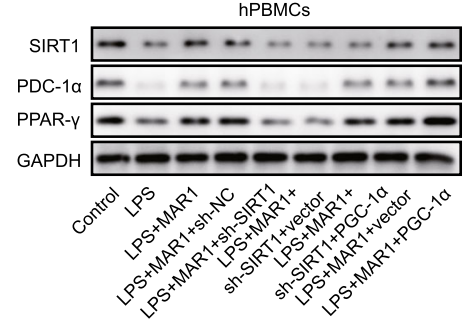

C
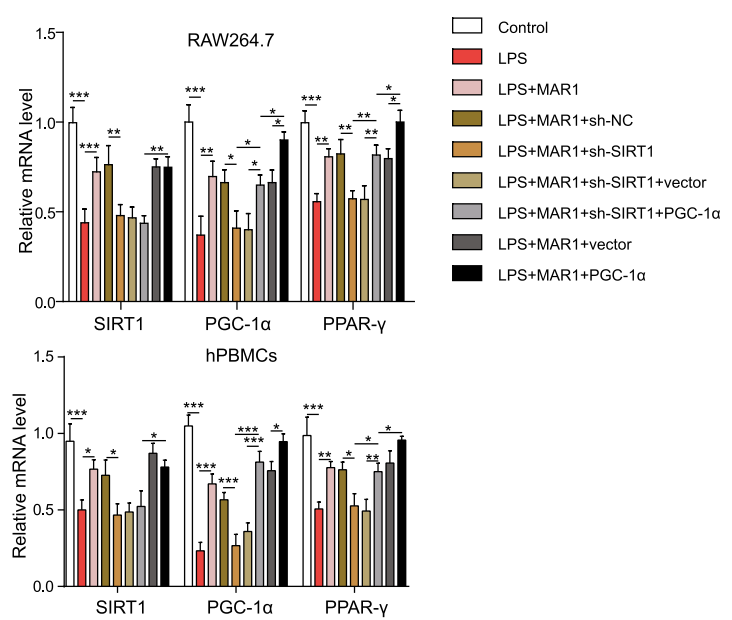
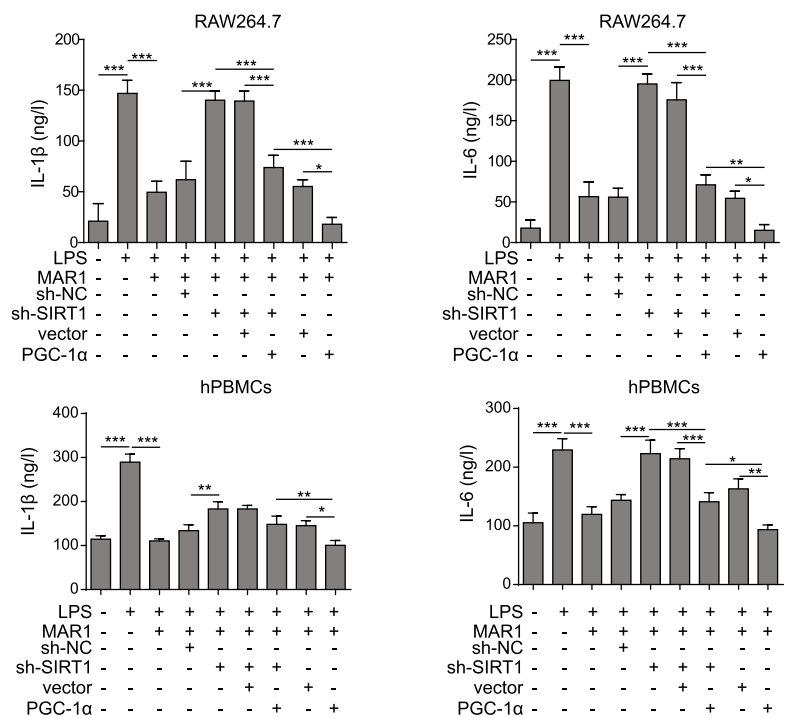

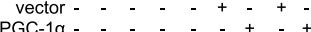

vector
PGC-1 $\alpha$ -
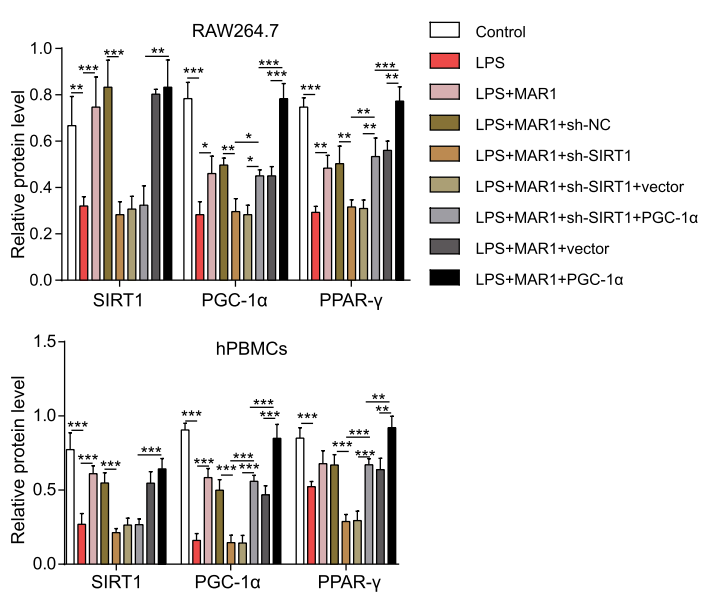

Fig. 4 (See legend on next page.) 
(See figure on previous page.)

Fig. 4 MAR1 suppressed inflammatory response in LPS-induced RAW 264.7 cells and hPBMCs via the SIRT1/PGC-1a/PPAR- $\gamma$ pathway. Cells were treated with LPS $(10 \mu \mathrm{g} / \mathrm{mL})$ for $24 \mathrm{~h}$ or treated with $10 \mathrm{nM}$ of MAR1 for $12 \mathrm{~h}$ before LPS treatment. $\mathbf{a}$, TNF- $\mathrm{a}$, IL-1 $\beta$ and IL-6 expression were detected by RT-qPCR; $\mathbf{b}$, TNF-a, IL-1 $\beta$ and IL-6 secretion were measured using ELISA. c-d, The mRNA and protein levels of SIRT1, PGC-1a and PPAR- $\gamma$ were detected by RT-qPCR and Western blot, respectively. Data were shown as the means \pm SD. Each experiment was repeated in triplicate. ${ }^{*} p<0.05,{ }^{* *} p<0.01,{ }^{* * *} p<0.001$

the proinflammatory cytokines IL-6, IL-1 $\beta$ and TNF$\alpha$ expression and secretion increased. Under the action of MAR1, the elevated levels of SIRT1, PGC-1 $\alpha$, and PPAR $-\gamma$ protein and inhibited the expression of proinflammatory factors and exerted anti-inflammatory effects were observed. In subsequent observations, we inhibited the expression of SIRT1 in RAW264.7 cells and hPBMCs by transfected with shRNA against SIRT1 to explore the role of SIRT1 in the antiinflammatory activity of MAR1. The results showed that the expression of PGC- $1 \alpha$ and PPAR- $\gamma$ protein was inhibited, the content of pro-inflammatory factors increased, and LPS-induced sepsis worsened. It was proved that SIRT1 was activated in RAW264.7 cells and hPBMCs under MAR1 treatment to reduce LPSinduced inflammatory response. At the same time, effect of suppressing SIRT1 expression was reversed by overexpression of PGC-1 $\alpha$. In summary, it can be concluded from the results of this study that MAR1 reduces the inflammatory response by activating the regulatory mechanism of the SIRT1/PGC-1 $\alpha /$ PPAR- $\gamma$ axis (Fig. 5).

The present study also has some limitations. It is an in vitro study, thus the in vivo effects of MAR1 on sepsis as well as its clinical effects are not clear. More researches are still necessary to confirm the in vivo and potential clinical application of MAR1 in sepsis treatment.

In conclusion, this study demonstrates that the SIRT1/ PGC- $1 \alpha /$ PPAR- $\gamma$ axis plays an important role in the process of MAR1 in reducing LPS-induced inflammation in in vitro sepsis model and provides clues for further exploring the mechanism of MAR1 in reducing inflammation in sepsis. Altogether, we propose that MAR1 could not only be a potential biomarker but also a novel therapeutic target for sepsis.

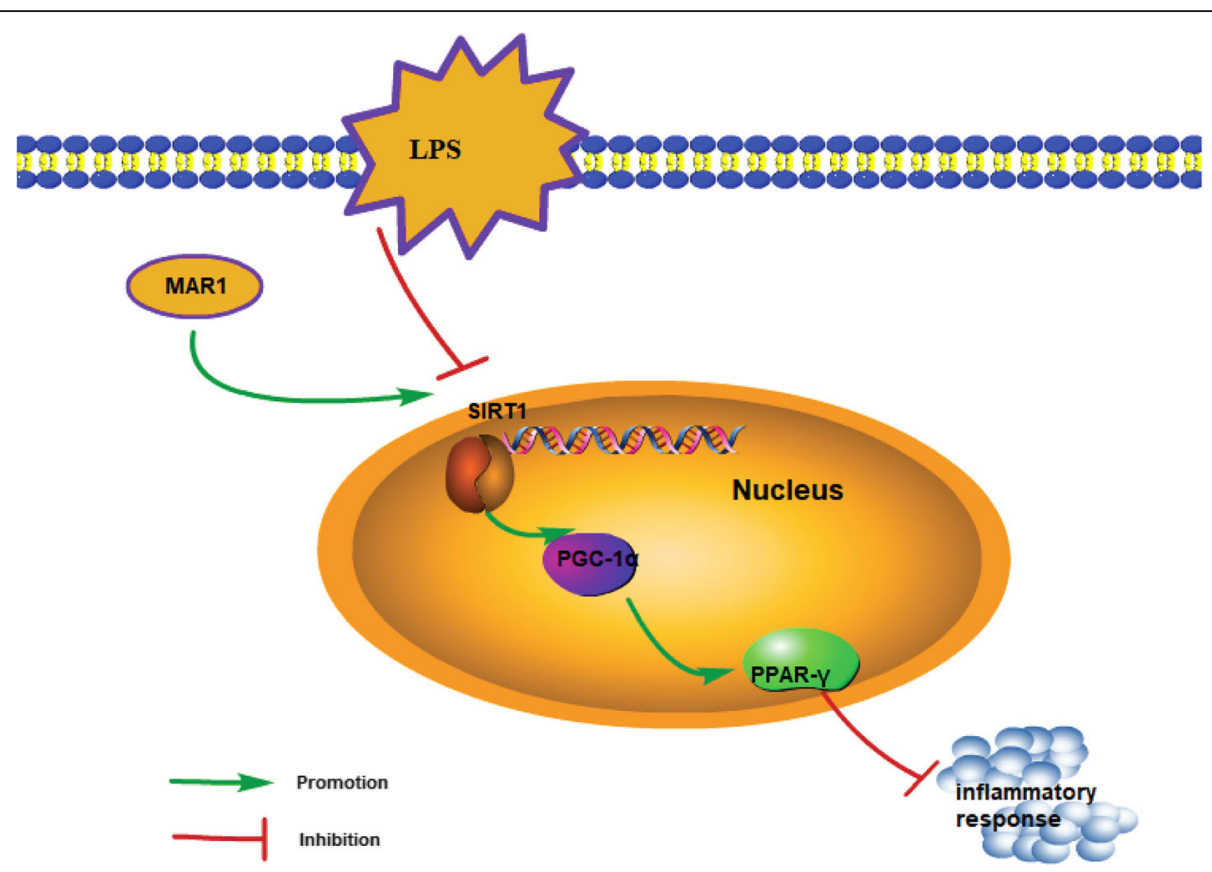

Fig. 5 The schematic diagram consisting of identified pathway showing that MAR1 reduces the inflammatory response by activating the regulatory mechanism of the SIRT1/PGC-1a/PPAR- $y$ axis 


\section{Acknowledgements}

Not applicable.

\section{Authors' contributions}

Guarantor of integrity of the entire study: Rui Chen; Study concepts: Wei Wang, Rong-Li Xu, Rui Chen; Study design: Wei Wang, Rong-Li Xu; Definition of intellectual content: Rong-Li Xu; Literature research: Ping He; Experimental studies: Rui Chen; Data acquisition: Rong-Li Xu; Data analysis: Wei Wang; Statistical analysis: Wei Wang, Rong-Li Xu; Manuscript preparation: Wei Wang, Rong-Li Xu; Manuscript editing: Wei Wang, Rong-Li Xu, Rui Chen; Manuscript review: Rui Chen. The author(s) read and approved the final manuscript.

\section{Funding}

None.

\section{Availability of data and materials}

All data generated or analysed during this study are included in this published article [and its supplementary information files].

\section{Ethics approval and consent to participate}

Not Applicable. This article does not contain any studies with human participants or animals performed by any of the authors.

\section{Consent for publication}

Not Applicable.

\section{Competing interests}

The authors declare that they have no conflict of interest.

\section{Author details}

'Department of Emergency, Hainan General Hospital, Hainan Affiliated Hospital of Hainan Medical University, No.19, Xiuhua Road, 570311 Haikou, Hainan Province, People's Republic of China. ${ }^{2}$ Department of Cardiology, Hainan General Hospital, Hainan Affiliated Hospital of Hainan Medical University, No.19, Xiuhua Road, 570311 Haikou, Hainan Province, People's Republic of China. ${ }^{3}$ Department of Medical Intensive Care Unit, General Hospital of Southern Theater Command, PLA, No.111, Liuhua Road, 510010 Guangzhou, People's Republic of China.

Received: 22 July 2020 Accepted: 21 January 2021

Published online: 08 February 2021

\section{References}

1. Angus DC, van der Poll T. Severe sepsis and septic shock. N Engl J Med. 2013:369(9):840-51.

2. Rello J, et al. Sepsis: A Review of Advances in Management. Adv Ther. 2017; 34(11):2393-411.

3. Cavaillon J-M, Adib-Conquy M. Monocytes/macrophages and sepsis. Crit Care Med. 2005:33(12):S506-9.

4. Qiu P, Liu Y, Zhang J. the role and mechanisms of macrophage autophagy in sepsis. Inflammation. 2019:42(1):6-19.

5. Hu SB, Zider A, Deng JC. When host defense goes awry: Modeling sepsisinduced immunosuppression. Drug Discovery Today Disease Models. 2012 9(1):e33-8.

6. Hung Y-L, et al. Corylin protects LPS-induced sepsis and attenuates LPSinduced inflammatory response. Sci Rep. 2017;7:46299.

7. Napier BA, et al. Western diet regulates immune status and the response to LPS-driven sepsis independent of diet-associated microbiome. Proc Nat Acad Sci. 2019;116(9):3688-94.

8. Pfeiffer D, et al. miR-146a, miR-146b, and miR-155 increase expression of IL-6 and IL-8 and support HSP10 in an in vitro sepsis model. PLoS One. 2017; 12(6):e0179850.

9. Chen L, et al. Sonchus oleraceus Linn protects against LPS-induced sepsis and inhibits inflammatory responses in RAW264. 7 cells. J Ethnopharmacol. 2019:236:63-9

10. Zhou W, et al. MicroRNA-205-5b inhibits HMGB1 expression in LPS-induced sepsis. Int J Mol Med. 2016;38(1):312-8.

11. Serhan $\mathrm{CN}$, et al. Protectins and maresins: New pro-resolving families of mediators in acute inflammation and resolution bioactive metabolome. Biochim Biophys Acta. 2015;1851(4):397-413.
12. Serhan CN. Pro-resolving lipid mediators are leads for resolution physiology. Nature. 2014:510(7503):92-101.

13. Serhan $\mathrm{CN}$, et al. Macrophage proresolving mediator maresin 1 stimulates tissue regeneration and controls pain. FASEB J. 2012;26(4):1755-65.

14. Schlegel $\mathrm{M}$, et al. Inhibition of neogenin fosters resolution of inflammation and tissue regeneration. J Clin Invest. 2018;128(10):4711-26.

15. Xian $\mathrm{W}$, et al. Maresin 1 attenuates the inflammatory response and mitochondrial damage in mice with cerebral ischemia/reperfusion in a SIRT1-dependent manner. Brain Res. 2019;1711:83-90.

16. Xian W, et al. The pro-resolving lipid mediator Maresin 1 protects against cerebral ischemia/reperfusion injury by attenuating the pro-inflammatory response. Biochem Biophys Res Commun. 2016;472(1):175-81.

17. Yuk JM, et al. Orphan Nuclear Receptor ERRalpha Controls Macrophage Metabolic Signaling and A20 Expression to Negatively Regulate TLR-Induced Inflammation. Immunity. 2015:43(1):80-91.

18. Xu S, et al. SIRT1/3 Activation by Resveratrol Attenuates Acute Kidney Injury in a Septic Rat Model. Oxid Med Cell Longev. 2016;2016:7296092.

19. Zhuo Y, et al. Resolvin D1 promotes SIRT1 expression to counteract the activation of STAT3 and NF-KB in mice with septic-associated lung injury. Inflammation. 2018;41(5):1762-71.

20. Quan M, et al. Tanshinone IIA protects against lipopolysaccharide-induced lung injury through targeting Sirt1. J Pharm Pharmacol. 2019;71(7):1142-51.

21. Gao $R$, et al. Sirt1 restrains lung inflammasome activation in a murine model of sepsis. Am J Physiol Lung Cell Mol Physiol. 2015;308(8):L847-53.

22. Scarpulla RC. Transcriptional paradigms in mammalian mitochondrial biogenesis and function. Physiol Rev. 2008;88(2):611-38.

23. Scarpulla RC. Metabolic control of mitochondrial biogenesis through the PGC-1 family regulatory network. Biochim Biophys Acta. 2011;1813(7): 1269-78.

24. Higashida $\mathrm{K}$, et al. Effects of resveratrol and SIRT1 on PGC-1alpha activity and mitochondrial biogenesis: a reevaluation. PLoS Biol. 2013;11(7): e1001603.

25. Makela J, et al. Peroxisome proliferator-activated receptor-gamma (PPARgamma) agonist is neuroprotective and stimulates PGC-1alpha expression and CREB phosphorylation in human dopaminergic neurons. Neuropharmacology. 2016;102:266-75.

26. Wang L, et al. Natural product agonists of peroxisome proliferator-activated receptor gamma (PPARgamma): a review. Biochem Pharmacol. 2014:92(1): 73-89.

27. Peng S, et al. PPAR-gamma Activation Prevents Septic Cardiac Dysfunction via Inhibition of Apoptosis and Necroptosis. Oxid Med Cell Longev. 2017; 2017:8326749.

28. Fang $\mathrm{Y}$, et al. LncRNA H19 functions as an Aquaporin 1 competitive endogenous RNA to regulate microRNA-874 expression in LPS sepsis. Biomed Pharmacother. 2018:105:1183-91.

29. Huang W, et al. Long non-coding RNA PVT1 promote LPS-induced septic acute kidney injury by regulating TNFalpha and JNK/NF-kappaB pathways in HK-2 cells. Int Immunopharmacol. 2017:47:134-40.

30. Zhong $W$, et al. Curcumin alleviates lipopolysaccharide induced sepsis and liver failure by suppression of oxidative stress-related inflammation via PI3K/AKT and NF-kappaB related signaling. Biomed Pharmacother. 2016:83:302-13

31. Vachharajani VT, et al. Sirtuins Link Inflammation and Metabolism. J Immunol Res. 2016;2016:8167273.

32. Gu J, et al. Maresin 1 attenuates mitochondrial dysfunction through the ALX/CAMP/ROS pathway in the cecal ligation and puncture mouse model and sepsis patients. Lab Invest. 2018;98(6):715-33.

33. Li R, et al. Maresin 1 Mitigates Inflammatory Response and Protects Mice from Sepsis. Mediators Inflamm. 2016;2016:3798465.

34. Serhan CN, et al. Maresins: novel macrophage mediators with potent antiinflammatory and proresolving actions. J Exp Med. 2009;206(1):15-23.

35. Gu Z, et al. Resolvin D1, resolvin D2 and maresin 1 activate the GSK3beta anti-inflammatory axis in TLR4-engaged human monocytes. Innate Immun. 2016;22(3):186-95.

36. Kou DQ, et al. Magnolol attenuates the inflammation and apoptosis through the activation of SIRT1 in experimental stroke rats. Pharmacol Rep. 2017;69(4):642-7.

37. Poulose N, Raju R. Sirtuin regulation in aging and injury. Biochim Biophys Acta. 2015;1852(11):2442-55.

38. Cho RL, et al. Heme oxygenase-1 induction by rosiglitazone via PKCalpha/ AMPKalpha/p38 MAPKalpha/SIRT1/PPARgamma pathway suppresses 
lipopolysaccharide-mediated pulmonary inflammation. Biochem Pharmacol. 2018;148:222-37.

39. Li HY, et al. Curcumin inhibits angiotensin II-induced inflammation and proliferation of rat vascular smooth muscle cells by elevating PPAR-gamma activity and reducing oxidative stress. Int J Mol Med. 2017;39(5):1307-16.

40. Yue L, et al. Adiponectin Protects against Glutamate-Induced Excitotoxicity via Activating SIRT1-Dependent PGC-1alpha Expression in HT22

Hippocampal Neurons. Oxid Med Cell Longev. 2016;2016:2957354.

\section{Publisher's Note}

Springer Nature remains neutral with regard to jurisdictional claims in published maps and institutional affiliations.

Ready to submit your research? Choose BMC and benefit from:

- fast, convenient online submission

- thorough peer review by experienced researchers in your field

- rapid publication on acceptance

- support for research data, including large and complex data types

- gold Open Access which fosters wider collaboration and increased citations

- maximum visibility for your research: over $100 \mathrm{M}$ website views per year

At $\mathrm{BMC}$, research is always in progress.

Learn more biomedcentral.com/submissions 